\title{
Numerical modelling of the reinforced concrete influence on a combined system of tunnel support
}

\author{
Bojana Grujićc Igor Jokanović $^{2}$, Žarko Grujić ${ }^{1}$, Dragana Zeljić1 \\ ${ }^{1}$ University of Novi Sad, Faculty of Civil Engineering, Subotica \\ e-mail: jokanovici@gf.uns.ac.rs, mila.svilar@gmail.com \\ ${ }^{2}$ University of Banja Luka, Faculty of Architecture, Civil Engineering and Geodesy, Banja Luka \\ e-mail: bojana.grujic@aggf.unibl.org,dragana.zeljic@aggf.unibl.org,zarko.grujic@aggf.unibl.org
}

\begin{abstract}
The paper presents the experimental, laboratory determined rheological-dynamic analysis of the properties of fiber reinforced concrete, which was then utilized to show nonlinear analysis of combined system of tunnel support structure. According to the performed experiments and calculations, different processes of destructive behavior of tunnel lining were simulated in combination with elastic and elastic-plastic behavior of materials taking into account the tunnel loading, the interaction between the fiber reinforced concrete and soil, as well as the interaction between the fiber reinforced concrete and the inner lining of the tunnel.
\end{abstract}

Key words: reinforced concrete, nonlinear analysis, combined system of the tunnel

\section{Introduction}

Fiber Reinforced Concrete (FRC) is a composite material with a cementitious matrix and discontinuous reinforcement (the fibers) that may be made of metal, glass or synthetic materials. After almost four decades of research, mechanical properties of FRC are well known and standards for material characterization are widely available, and design guidelines have been recently proposed by RILEM. Among the structural applications of FRC, there is a growing interest to be used with the tunnel structures, where steel fibers may substitute conventional reinforcement concrete partially or totally.

The structural behavior of tunnel structures is numerically simulated with finite element analysis based on nonlinear fracture mechanics. The excavated Klašnice tunnel at the motorway E661 in Bosnia and Herzegovina has a diameter of about 5,85 m, and with the length of $477 \mathrm{~m}$ is located about 11 to $21 \mathrm{~m}$ below the surface. The study showed that the lining of conventional reinforced concrete can be replaced by FRC, having suitable thickness, with minimal total displacement. After the experimental characterization of the mechanical properties of Steel Fiber Reinforced Concrete (SFRC), FEM (Finite Element Method) 
analysis allowed to study the structural behavior of the tunnel lining with different types of reinforcement under significant loading conditions.

\section{Materials}

The experimental characterization of the material properties of SFRC was performed on a concrete matrix used for the Klašnice tunnel. SFRC was made with cement CEM I 42.5 R, a rounded shape natural river gravel having maximum diameter of $12 \mathrm{~mm}$. Its composition is summarized in Table 1.

Table 1: The percentage content of the aggregate used

\begin{tabular}{|l|c|c|c|c|c|c|c|c|c|c|c|c|}
\hline \multirow{2}{*}{ Fraction } & \multicolumn{10}{|c|}{ Percentage of passage on sieve (mm) } \\
\cline { 2 - 13 } & 0,125 & 0,25 & 0,5 & 0,71 & 1 & 2 & 4 & 8 & 11,2 & 16 & 22,4 & 31,5 \\
\hline $0 / 4 \mathrm{~mm}$ & 1 & 5 & 30 & 45 & 55 & 80 & 95 & 100 & 100 & 100 & 100 & 100 \\
$4 / 8 \mathrm{~mm}$ & 0 & 0 & 0 & 0 & 0 & 0 & 4 & 95 & 100 & 100 & 100 & 100 \\
$8 / 16 \mathrm{~mm}$ & 0 & 0 & 0 & 0 & 0 & 0 & 0 & 2 & 47 & 100 & 100 & 100 \\
\hline
\end{tabular}

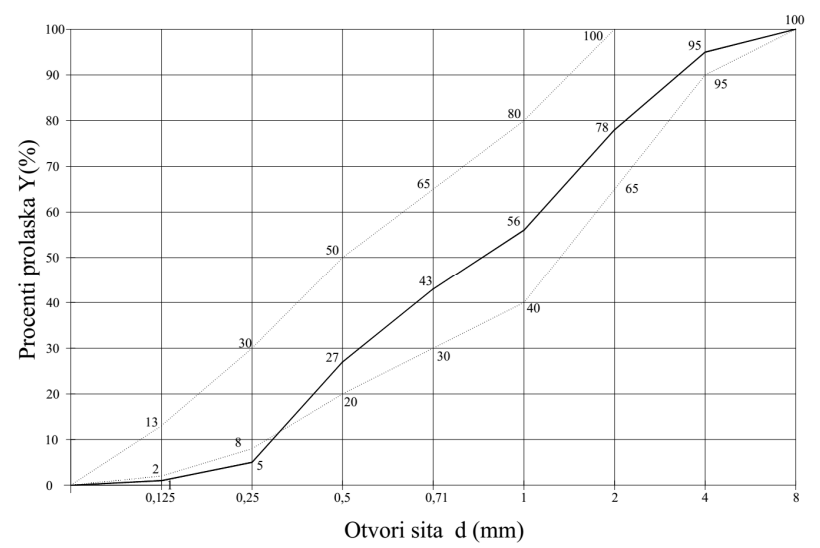

Figure 1: Granulometric curve aggregate fractions used for samples preparation

Within the experimental work, the basic properties and characteristics of the applied types of fibers were examined in laboratory (Table 2). The used steel fibers are made of pure steel, as well as mixtures of steel and aluminum. This feature of the non-uniformity of the applied fiber materials influenced the final properties of the fibers, which is evident from Table 2.

Table 2: Characteristics of applied steel fibers within the experiment

\begin{tabular}{|l|c|c|c|}
\hline Properties & $\mathrm{L}=50$ & $\mathrm{~L}=31$ & $\mathrm{~L}=25$ \\
\hline Shape & & & 25 \\
Length $(\mathrm{mm})$ & 50 & 31 & 0,75 \\
Diameter $(\mathrm{mm})$ & 0,75 & 0,75 & 34 \\
Ratio factor L/D & 67 & 41 & 7400 \\
Density $\left(\mathrm{kg} / \mathrm{m}^{3}\right)$ & 7100 & 7350 & 1300 \\
Tensile strength $(\mathrm{MPa})$ & 1150 & 1250 & \\
\hline
\end{tabular}




\section{Results of the experimental research}

\subsection{Modulus of elasticity}

The paper gives an overview of the determination of the modulus of elasticity of a cylindrical sample. The procedure is repeated in a series of three samples, and then the mean value of the elasticity module is taken.

Table 3: Determination of elasticity modulus of a cylindrical fiber reinforced concrete sample, measuring $150 \times 300 \mathrm{~mm}, 2 \%$ of steel fibers $\mathrm{L} / \mathrm{D}=50 / 0,75$

\begin{tabular}{|c|c|c|c|c|c|}
\hline \multicolumn{6}{|c|}{ Modulus of elasticity E - sample number 1, Etalon } \\
$\begin{array}{c}\text { Measuring place } \\
\text { dilatation } 10^{-3}(\mathrm{~mm})\end{array}$ & \multicolumn{5}{|c|}{ Force $(\mathrm{kN})$} \\
\hline 1 & 0 & 20 & 140 & 240 & 460 \\
\hline 2 & 0 & 4 & 45 & & \\
\hline 3 & 0 & 4 & 15 & & \\
\hline 4 & 0 & 1 & 21 & & \\
\hline 5 & 0 & 1 & 4 & & \\
\hline 6 & 0 & 0 & 3 & & \\
\hline 1 & & 18 & 38 & & \\
\hline 2 & & 3 & 18 & & \\
\hline 3 & & 1 & 19 & & \\
\hline 4 & & 1 & 5 & & \\
\hline 5 & & 0 & 4 & & \\
\hline 6 & & 9 & 35 & 90 & 200 \\
\hline 1 & & 7 & 16 & 30 & 65 \\
\hline 2 & & 2 & 3 & 7 & 20 \\
\hline 3 & & 0 & 2 & 5 & 20 \\
\hline 4 & & 0 & 1 & 2 & 5 \\
\hline 5 & & & & & \\
\hline 6 & & 0 & 15 & 50 & 110 \\
\hline
\end{tabular}

Based on the performed tests, the mean values of the elasticity modules $\mathrm{E}$ are calculated for standard samples as well as for micro-reinforced concrete samples with different content of steel fiber with the shape factor $\mathrm{L} / \mathrm{D}=50 / 0,75$ (fiber content of $1 \%, 2 \%$ and $3 \%$ ).

Elasticity modules $\mathrm{E}$ are calculated through the following equation:

$$
\mathrm{E}=\Delta \sigma / \Delta \varepsilon
$$

where:

$\Delta \sigma=\sigma_{\mathrm{g}}-\sigma_{\mathrm{d}}(\sigma-$ tensile stress $)$;

$\sigma_{\mathrm{g}}=\mathrm{f}_{\mathrm{p}} / 3$ (the upper limit of the selected tensile strength)

$\sigma_{\mathrm{d}}=0,5 \mathrm{MPa}$ (the lower limit of the selected tensile strength);

$\Delta \varepsilon$ - the difference in the mean values of the dilations corresponding to $\sigma_{\mathrm{g}}$ and $\sigma_{\mathrm{d}}$;

$f_{p}$ - the pressure at which the sample breaks. 
Figure 2. presents results of the rheological-dynamic model of material behavior in the standard concrete cylinder $(300 \times 150 \mathrm{~mm})$ on the basis of the experimental data from Table 4. As visible, with the increase of fibers quantity the Poison's coefficient $(\mu)$ decreases. Further, on the basis of the tests carried out, this means that the composite material, such as FRC, is a crude material in comparison with the standard concrete, and therefore the FRC has a higher deformability. This is a very important fact that needs to be emphasized when analyzing FRC. In terms of the $\sigma-\varepsilon$ diagram, deformation at the compressive strength $\varepsilon_{\mathrm{fc}}$ as

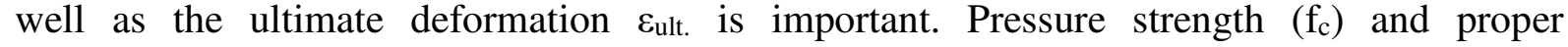
deformation are consistent with all four concrete samples with experimental data.

It is usual to perform quasi-static analysis of these diagrams and fracture energy, i.e. pressure toughness $\left(\mathrm{G}_{\mathrm{C}}\right)$ Also, the minimum coefficient of fracture $\left(\mathrm{f}_{\mathrm{c}} / \mathrm{G}_{\mathrm{C}}\right)$ determines the most favorable mix of concrete in the cylinder.

Table 4: Results of modulus of elasticity of standard and FRC concrete ( $\mathrm{L} / \mathrm{D}=50 / 0,75)$

1. Characteristics of the sample of concrete/etalon without fiber:

$\mathrm{F}_{\mathrm{c}, 28}=37,60 \mathrm{Mpa}$

\begin{tabular}{|l|l|l|l|l|}
\hline$\rho\left(\mathrm{kg} / \mathrm{m}^{3}\right)$ & $\mathrm{E}_{\mathrm{h}}(\mathrm{Mpa})$ & $\mathrm{E}_{\mathrm{d}}(\mathrm{Mpa})$ & $\mu$ & $\varepsilon(\mathrm{mm})$ \\
\hline 2195,38 & 19917,05 & 24877,312 & 0,188 & 0,003 \\
\hline
\end{tabular}

2. Characteristics of the sample of FRC with fiber content:

$\mathrm{V}_{\mathrm{f}}=1 \%$ in $1 \mathrm{~m}^{3}$ of concrete

$\mathrm{F}_{\mathrm{c}, 28}=38,00 \mathrm{Mpa}$

\begin{tabular}{|l|l|l|l|l|}
\hline$\rho\left(\mathrm{kg} / \mathrm{m}^{3}\right)$ & $\mathrm{E}_{\mathrm{h}}(\mathrm{Mpa})$ & $\mathrm{E}_{\mathrm{d}}(\mathrm{Mpa})$ & $\mu$ & $\varepsilon(\mathrm{mm})$ \\
\hline 2210,16 & 20879,16 & 26079,95 & 0,1685 & 0,0033 \\
\hline
\end{tabular}

3. Characteristics of the sample of FRC with fiber content:

$\mathrm{V}_{\mathrm{f}}=2 \%$ in $1 \mathrm{~m}^{3}$ of concrete

$\mathrm{F}_{\mathrm{c}, 28}=38,7 \mathrm{Mpa}$

\begin{tabular}{|l|l|l|l|l|}
\hline$\rho\left(\mathrm{kg} / \mathrm{m}^{3}\right)$ & $\mathrm{E}_{\mathrm{h}}(\mathrm{Mpa})$ & $\mathrm{E}_{\mathrm{d}}(\mathrm{Mpa})$ & $\mu$ & $\varepsilon(\mathrm{mm})$ \\
\hline 2235,64 & 22061,4 & 27557,75 & 0,1565 & 0,0034 \\
\hline
\end{tabular}

4. Characteristics of fibersample FRC with fiber content:

$\mathrm{V}_{\mathrm{f}}=3 \%$ in $1 \mathrm{~m}^{3}$ of concrete

$\mathrm{F}_{\mathrm{c}, 28}=40,00 \mathrm{Mpa}$

\begin{tabular}{|l|l|l|l|l|}
\hline$\rho\left(\mathrm{kg} / \mathrm{m}^{3}\right)$ & $\mathrm{E}_{\mathrm{h}}(\mathrm{Mpa})$ & $\mathrm{E}_{\mathrm{d}}(\mathrm{Mpa})$ & $\mu$ & $\varepsilon(\mathrm{mm})$ \\
\hline 2258,23 & 22182,95 & 27709,68 & 0,1373 & 0,0042 \\
\hline
\end{tabular}

Note: $\mathrm{V}_{\mathrm{f}}$ - content of fibers; $\mathrm{F}_{\mathrm{c}, 28}$ - pressure strength after 28 days

Table 5: Results of rheological-dynamic analysis of FRC ( $\mathrm{L} / \mathrm{D}=50 / 0,75)$

\begin{tabular}{|c|c|c|c|c|c|}
\hline Concrete & $\mathrm{f}_{\mathrm{c}, 28}$ & $\varepsilon_{\mathrm{fc}}$ & $\varepsilon_{\text {ult. }}$ & $\mathrm{G}_{\mathrm{C}}(\mathrm{N} / \mathrm{mm})$ & $\mathrm{f}_{\mathrm{c}} / \mathrm{G}_{\mathrm{C}}$ \\
Etalon & 37,6 & 0,003 & 0,004794 & 21,0711 & 1,784 \\
$\mathrm{~V}_{\mathrm{f}}=1 \%$ & 38,0 & 0,0033 & 0,004979 & 20,0526 & 1,895 \\
$\mathrm{~V}_{\mathrm{f}}=2 \%$ & 38,7 & 0,0034 & 0,004954 & 19,1411 & 2,022 \\
$\mathrm{~V}_{\mathrm{f}}=3 \%$ & 40,0 & 0,0042 & 0,005791 & 20,3057 & 1,970 \\
\hline
\end{tabular}




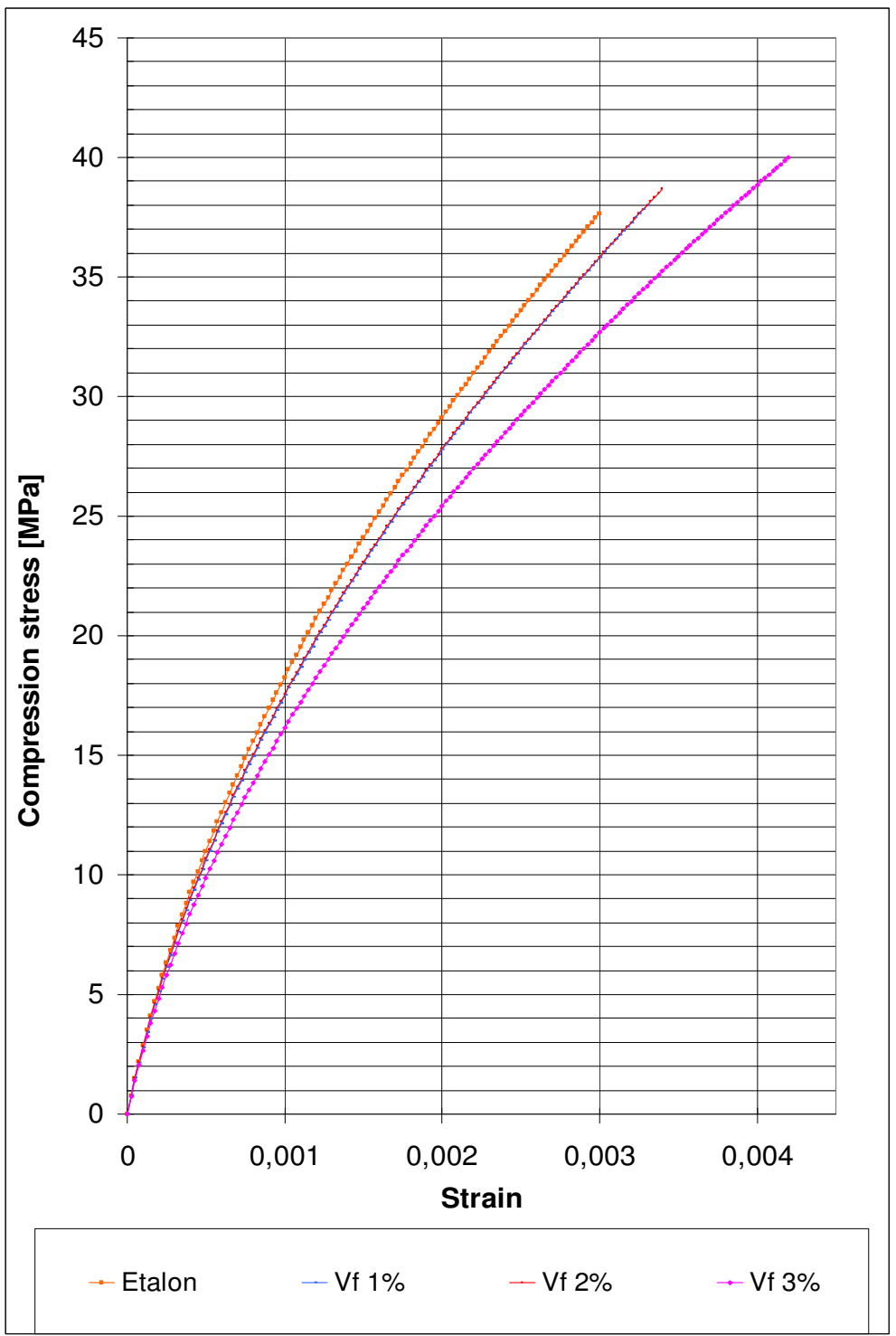

Figure 2: Graphical representation of the rheology-dynamic model for fibers $L / D=50 / 0,75$

\subsection{Tensile Strength Testing}

Although the tensile strength of the concrete during tightening is considerably less than the compressive strength of the concrete, the knowledge of the tensile strength of the concrete during tension is useful in determining when the cracks will begin to develop. Cracks represent the lack of concrete which significantly affects the physical and mechanical properties of concrete as well as the durability of concrete structures. The tensile strength depends primarily on the type of aggregate, the content of cement, the water-cement factor, the type and quantity of fibers, the shape of the fibers, the technological procedures for the preparation, installation and care of concrete. Results of testing tensile strength are given in Table 6. 
Table 6: Tensile strength results depending on the fiber types and amount

\begin{tabular}{|c|c|c|c|c|c|c|c|}
\hline \multicolumn{4}{|c|}{ Characteristics of used fibers } & \multirow[b]{2}{*}{$\begin{array}{l}\text { Fiber } \\
\text { content }\end{array}$} & \multicolumn{3}{|c|}{ Tensile strength } \\
\hline Fiber shape & $\begin{array}{c}\mathrm{L} \\
{[\mathrm{mm}]}\end{array}$ & $\begin{array}{c}\mathrm{D} \\
{[\mathrm{mm}]}\end{array}$ & $\mathrm{L} / \mathrm{D}$ & & $\begin{array}{c}\text { Etalon } \\
\text { (concrete } \\
\text { without } \\
\text { fiber) } \\
\text { [Mpa] }\end{array}$ & $\begin{array}{c}\text { Micro- } \\
\text { reinforced } \\
\text { concrete } \\
\text { [Mpa] }\end{array}$ & $\begin{array}{c}\text { Increase in } \\
\text { tensile } \\
\text { strength } \\
\%\end{array}$ \\
\hline & $\begin{array}{l}50 \\
50 \\
50\end{array}$ & 0,75 & 67 & $\begin{array}{l}1 \\
2 \\
3\end{array}$ & $\begin{array}{l}6,0 \\
6,0 \\
6,0\end{array}$ & $\begin{array}{c}11,59 \\
12,0 \\
11,7\end{array}$ & $\begin{array}{c}93,16 \\
100 \\
95\end{array}$ \\
\hline & $\begin{array}{l}31 \\
31 \\
31\end{array}$ & 0,75 & 41 & $\begin{array}{l}1 \\
2 \\
3\end{array}$ & $\begin{array}{l}6,0 \\
6,0 \\
6,0\end{array}$ & $\begin{array}{l}9,5 \\
9,4 \\
9,4\end{array}$ & $\begin{array}{l}58,33 \\
56,66 \\
56,66\end{array}$ \\
\hline & $\begin{array}{l}25 \\
25 \\
25\end{array}$ & 0,75 & 25 & $\begin{array}{l}1 \\
2 \\
3\end{array}$ & $\begin{array}{l}6,0 \\
6,0 \\
6,0\end{array}$ & $\begin{array}{l}7,8 \\
7,9 \\
8,0\end{array}$ & $\begin{array}{c}30 \\
31,66 \\
33,33\end{array}$ \\
\hline
\end{tabular}

\subsection{Bending strength}

The influence of steel fibers on the bending strength of the FRC is much higher than on the compressive strength and tensile strength. Usually, two strengths are provided for bending elements. The first called "strength at first cracking" corresponds to the load diagram - the angle of the point to which the diagram is approximately linear (point A, Figure 3.), and the second, called "boundary strength', corresponds to the maximum tension achieved, in the Figure 3. This is the point $\mathrm{C}$ which corresponds to the maximum load.

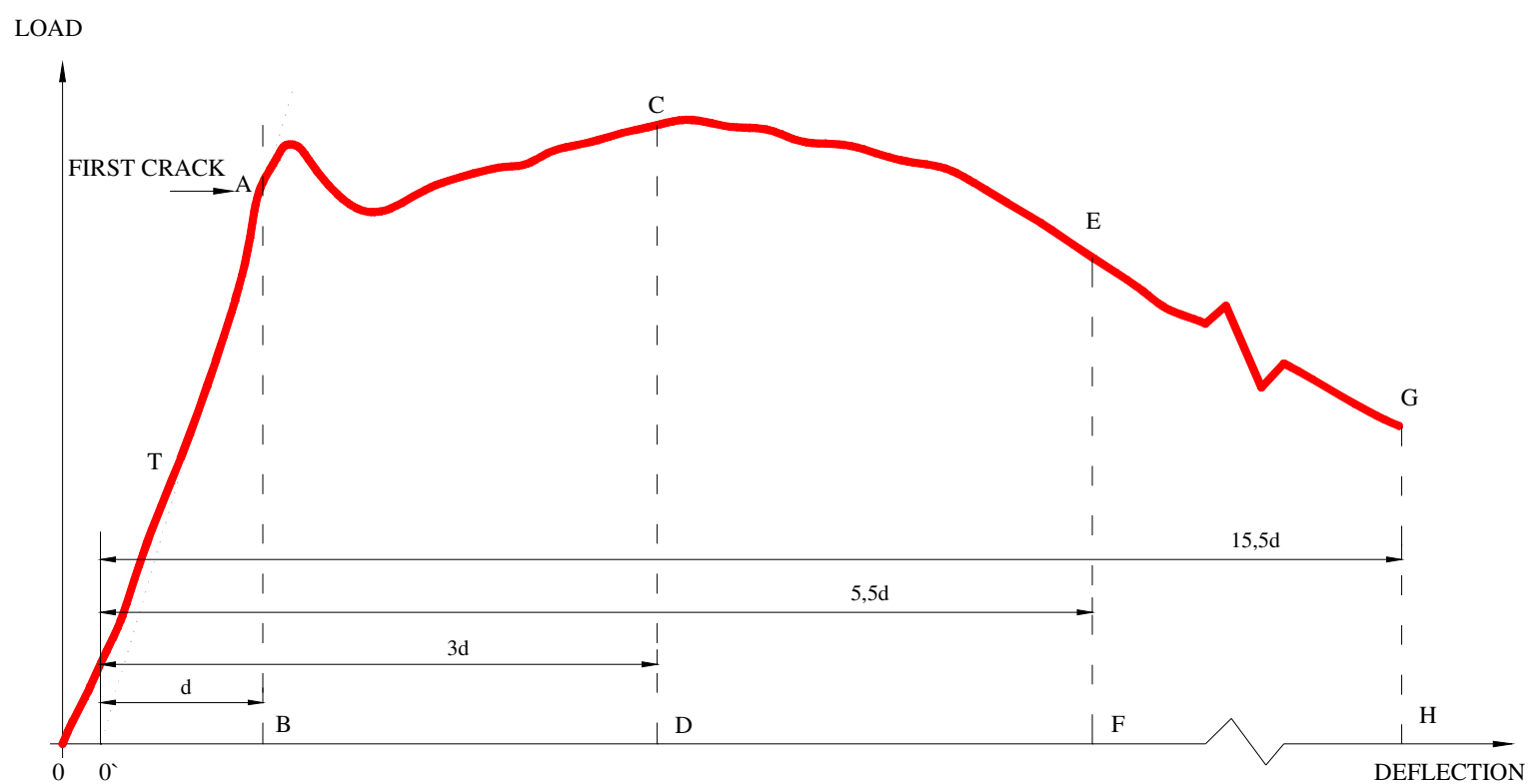

Figure 3: Diagram load - deflection for FRC, beam 100x100x400 mm 


\section{Description of the applied model for tunnel structure}

Numerical methods, in particular FEM, represent a valuable contribution to a much more accurate estimation of the tensile and displacement in tunnels and surrounding rock masses. But the FEM is useful only if a numerical method is applied that correctly describes the natural behavior of the rock mass.

Choosing the model of the tunnel structure, the quality of the rock mass, the degree of variability and quality along the tunnel are respected. Construction technology and the height of the overheads also have an impact on this choice. The cross-section is a complex figure in the shape of figure of $5,85 \mathrm{~m}$, a protruding height of $2,00 \mathrm{~m}$ and a foot bucket that closes the entire contour. This type of tunnel extends through the geotechnical model A of the tunnel with the characteristics given in a Table 7.

Table 7: Model A for Coulomb-Mohr

$\begin{array}{ll}\text { Geotechnical data: } & \text { diabase formation } \\ \gamma\left(\mathrm{kN} / \mathrm{m}^{3}\right) & 25 \\ \varphi\left({ }^{\circ}\right) & 25 \\ \text { E (Mpa) } & 2000 \\ \nu(-) & 0,28 \\ \text { c (Mpa) } & 0,20 \\ \text { D (Mpa) } & 120\end{array}$

\subsection{Introductory notes for the numerical model}

A model of a traffic tunnel was adopted for numerical testing of the comparison of the behavior of the excavation insurance (Figure 4). The shown comparison is the behavior of the excavating contour:

- using a conventional concrete class 30 reinforced with two-layer steel grid;

- using FRC class 38.7 reinforced steel fibers with curved ends and shape factor $\mathrm{L} / \mathrm{D}=$ $50 / 0,75$ and the amount of fiber present $2 \%$ compared to the total concrete mixture.

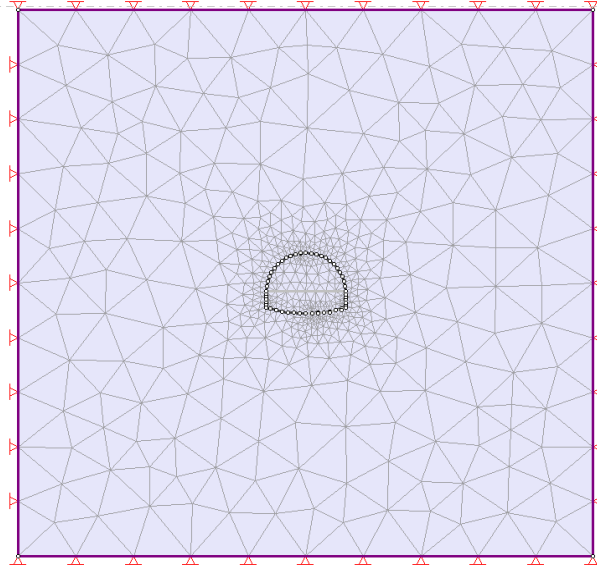

Figure 4: Basic model of tunnel and the surrounding rock geotechnical characteristics
Material: material 1

Initial element loading: field stress \& body force

Unit weight: $0,025 \mathrm{MN} / \mathrm{m}^{3}$

Elastic type: isotropic

Young's modulus: $2000 \mathrm{Mpa}$

Poisson's ratio: 0,28

Failure criterion: Mohr-Coulomb

Tensile strength: $0 \mathrm{Mpa}$

Peak friction angle: 25 degrees

Peak cohesion: 0,2 Mpa

Material type: plastic

Dilation angle: 0 degrees

Residual friction angle: 25 degrees

Residual cohesion: 0,2 Mpa

Piezo to use: none

$\mathrm{R}_{\mathrm{u}}$ value: / 
The aim of this numerical analysis was to show the behavior of the rock mass around the excavation in the case of applying the FRC with characteristic $\mathrm{L} / \mathrm{D}=50 / 0,75$ with emphasis on the substantially increased tensile strength of this concrete and for all other parameters of the same for both cases: geotechnical characteristics of the rock mass, load during phase of excavation and compressive strength of basic material e.g. reinforced concrete. Passive anchors are not installed because they are not important for this study.

The reinforced concrete lining is treated as a shaft element because it is capable of reinforcing the normal forces, transverse forces and bending moments.

In the software PHASE2v6 total displacements for the two phases of the excavation were compared, depending on the thickness of the tunnel lining for reinforced concrete and fiber reinforced concrete (Table 8).

Table 8: MaxU $U_{\text {tot }}$ (maximum displacement) for models processed in PHASE2v6 depending on the thickness of the tunnel lining D

\begin{tabular}{|c|c|c|}
\hline \multirow{2}{*}{$\mathrm{D}(\mathrm{cm})$} & \multicolumn{2}{|c|}{$\max \mathrm{U}_{\text {tot }}$} \\
\cline { 2 - 3 } & $1^{\text {st }}$ phase & $2^{\text {nd }}$ phase \\
\hline RC 15 & 0,00661257 & 0,00607221 \\
\hline RC 20 & 0,00661257 & 0,00605811 \\
\hline RC 25 & 0,00667319 & 0,00604121 \\
\hline FRC 15 & 0,00654235 & 0,00608391 \\
\hline FRC 20 & 0,00661257 & 0,00605811 \\
\hline FRC 25 & 0,00667319 & 0,00604121 \\
\hline
\end{tabular}

\section{Conclusion}

The use of FRC with steel fibers, with curved ends, and a shape factor L/D = 50/0,75 in an amount of $2 \%$ in weight of concrete gives excellent results in the tunnel structure calculation. In doing so, the total displacement of the FRC tunnel coating corresponds to the total displacement of the tunnel lining of reinforced concrete. This demonstrates the possibility of using the FRC in the calculation of underground objects instead of reinforced concrete coating, with one great note that the FRC manufacturing technology and the homogeneity of the concrete mix represent a key factor for the good indicators and properties of the tested micro-reinforced composite.

\section{References}

[1] Guide to Durable Concrete, ACI Committee 201.2R-08. American Concrete Institute. 2008

[2] Šušterič, J., Zajc, A., Lekovar, I. Surface characteristics of fiber reinforced concrete. Industrieböden, 2003, Band 1, p. 255-261.

[3] Milašinović, D.D. Rheological-dynamical analogy: prediction of buckling curves of columns. International Journal of Solid Structures, vol. 29, 2000, no 29, p. 3965-4004.

[4] Grujić, B. Modeling of physical and mechanical properties of fiber reinforced concrete for application in constructions. PhD Thesis. Faculty of Architecture, Civil Engineering and Geodesy, Banja Luka, 2016. 